\title{
Tensile Property, Corrosion Resistance and Cytocompatibility of Tungsten Short Fiber Reinforced Ti-6Al-4V Alloy
}

\author{
Masaaki Koganemaru ${ }^{1}$, Yoshimitsu Okazaki ${ }^{2}$, Emiko Nishimura $^{3}$, Shinichi Nishida ${ }^{4}$, \\ Kouichi Nakano ${ }^{5}$, Yuji Yanagida ${ }^{6}$ and Hidetoshi Tamasaki ${ }^{7}$ \\ ${ }^{1}$ Mechanics \& Electronics Research Institute, Fukuoka Industrial Technology Center, Kitakyusyu 807-0831, Japan \\ ${ }^{2}$ Institute of Mechanical Systems Engineering, National Institute of Advanced Industrial Science and Technology (AIST), \\ Tsukuba 305-8564, Japan \\ ${ }^{3}$ Independent Administrative Institution, National Institute of Technology and Evaluation, Tsukuba 305-0044, Japan \\ ${ }^{4}$ Department of Mechanical Engineering, Faculty of Science and Engineering, Saga University, Saga 840-0852, Japan \\ ${ }^{5}$ Technology Research \& Development Department, Takada Corporation, Kitakyusyu 808-0143, Japan \\ ${ }^{6}$ Reserch Laboratory, Kuroki Kogyosho Co., Ltd, Kitakyusyu 806-0012, Japan \\ ${ }^{7}$ Technical Div., Nippon Steel Bolten Co., Ltd., Yukuhashi 824-0038, Japan
}

Tungsten short fiber reinforced Ti-6Al-4V alloy has been investigated in terms of its tensile properties, corrosion resistance and cytocompatibility. This composite material was fabricated by a hot isostatic pressing process. The room temperature tensile strength and the $0.2 \%$ proof stress were very high, approximately $1300 \mathrm{MPa}$ and $1200 \mathrm{MPa}$, respectively. These strengths are excellent compared to those of the existing biomaterial of titanium-base. The cytocompatibility of this composite material was evaluated using the anodic polarization test and the cytocompatibility test to clarify the possibility of its application as a structural biomaterial. Anodic polarization tests in Eagle's minimum essential medium and in 1 mass\% lactic acid were carried out to investigate the corrosion resistance of the composite material in vivo. The current density at the entrance to the passive region of the composite material tended to increase more than that of Ti-6Al-4V alloy. However, the passive region was retained at a potential of about $2 \mathrm{~V}$, which is sufficiently high compared to the potential in vivo. In addition, the cytocompatibility was evaluated by investigating the relative growth ratio of fibroblast L929 cells after four days incubation on the test material. The relative growth ratio is obtained as follows: number of cells on the test material/number of cells on the reference material (control). The relative growth ratio of the composite material in making Ti-6Al-4V alloy into a control was 0.9032 . According to the result of ICP-MS analysis, the concentration of tungsten in the medium after four days of incubation on the composite material was high compared to that of titanium, aluminum and vanadium.

(Received May 23, 2002; Accepted August 27, 2002)

Keywords: mechanical property, corrosion resistance, cytocompatibility, titanium alloy, tungsten short fiber, metal matrix composite (MMC), hot isostatic pressing (HIP)

\section{Introduction}

New structural biomaterials which will have various purposes have been recently developed, with a particular focus on new titanium alloys. Two of the various purposes include, first, the development of the titanium alloy without vanadium and aluminum which has excellent cytocompatibility ${ }^{1-6)}$ and second, the development of the titanium alloy with a low elastic modulus approximately equal to the elastic modulus of bone. ${ }^{7)}$ However, for the above new structural biomaterials the composite material technology has not been used, which is very useful for the development and the design of new biomaterials, particularly in extreme environments, because for the composite material there are numerous design varieties and it is possible to carry out active material design. ${ }^{8}$ )

Some of the authors have recently developed the tungsten short fiber reinforced Ti-6Al-4V alloy composite. ${ }^{9)}$ The concept is based on developing the light and high tensile strength titanium-base material. In this study, the above composite material has been investigated in terms of its tensile properties, corrosion resistance and cytocompatibility. The corrosion resistance was evaluated by the anodic polarization test. The anodic polarization test can evaluate the stability of the passive film on the material surface for corrosion resistance. ${ }^{2)}$ The cytocompatibility is evaluated by investigating the relative growth ratio of culture cells on the test material. ${ }^{10)}$ It is important to evaluate the cytocompatibility of this composite material, because there are few reports on the cytocompatibility of tungsten. In this paper, the authors refer to the process of the tungsten short fiber reinforced $\mathrm{Ti}-6 \mathrm{Al}-4 \mathrm{~V}$ alloy composite and the results of its cytocompatibility tests.

\section{Materials}

The tungsten short fiber reinforced $\mathrm{Ti}-6 \mathrm{Al}-4 \mathrm{~V}$ alloy (6$4 \mathrm{Ti}-\mathrm{W}$ composite) was made by powder metallurgy. Tungsten short fibers and $\mathrm{Ti}-6 \mathrm{Al}-4 \mathrm{~V}$ powder were compounded using the HIP (Hot Isostatic Pressing) process. Table 1 lists the chemical compositions of $\mathrm{Ti}-6 \mathrm{Al}-4 \mathrm{~V}$ powder that was manufactured by the atomization method. The average particle size is about $100 \mu \mathrm{m}$ in diameter. The nominal tensile strength and the diameter of the tungsten fiber are $3430 \mathrm{MPa}$ and $20 \mu \mathrm{m}$, respectively. In addition, the measured average length of the fiber was approximately $1 \mathrm{~mm}$. Because the

Table 1 Chemical composition of Ti-6Al-4V alloy particle.

\begin{tabular}{cccccccc}
\hline Al & V & Fe & O & C & N & H & Ti \\
\hline 6.14 & 3.93 & 0.17 & 0.19 & 0.011 & 0.014 & 0.009 & bal. \\
\hline
\end{tabular}

(mass\%) 
Tungsten short fiber

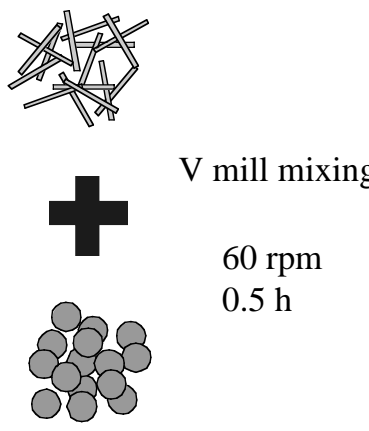

Ti-6Al-4V particle

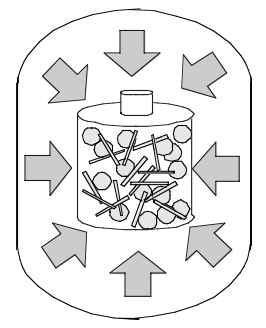

Hot Isostatic Pressing (HIP)

$950^{\circ} \mathrm{C}$

$100 \mathrm{MPa}$

$1 \mathrm{~h}$

\section{Sintered compact}

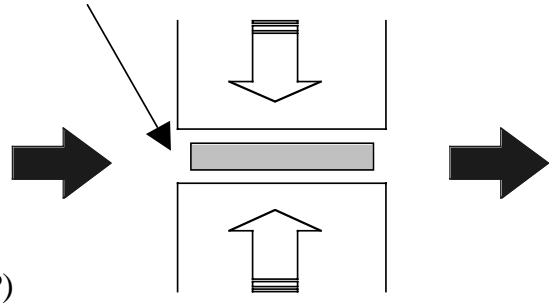

Hot forging

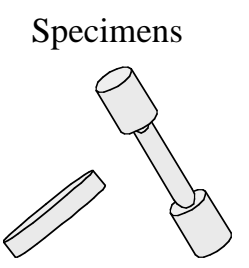

Machining

Fig. 1 Flow chart for manufacturing of tungsten short fiber reinforced Ti-6Al-4V alloy.

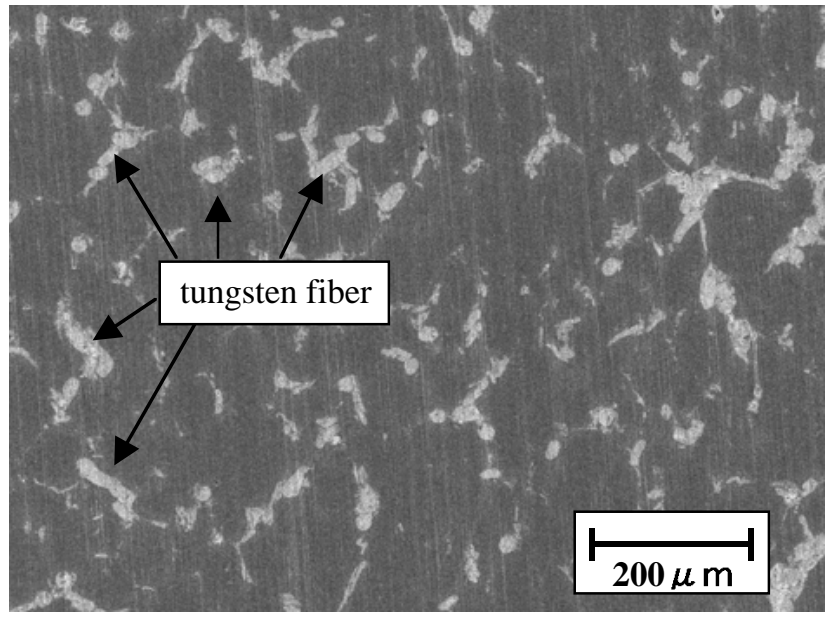

Fig. 2 Surface observation result of composite material.

melting point of tungsten is very high and the mechanical property of the small-diameter fiber would be neither greatly affected nor damaged under the present HIP process, tungsten fiber was selected for reinforcement.

Figure 1 shows the flow chart for manufacturing 6-4Ti-W composite. Tungsten short fibers and Ti-6Al-4V alloy powder were mixed with a $9 \%$ volume fraction of fiber using a Vmill mixer at $60 \mathrm{rpm}$ for $1 \mathrm{~h}$, then the HIP process was carried out. The conditions of the HIP process were $100 \mathrm{MPa}$ pressure at $950^{\circ} \mathrm{C}$ for $1 \mathrm{~h}$ in argon gas. This temperature condition was controlled to be under the transformation temperature of Ti-6Al-4V alloy for the composite matrix to retain its microstructure or crystal grain which has excellent mechanical properties. After HIP treatment, hot forging was conducted at $900^{\circ} \mathrm{C}$. The Ti-6Al-4V alloy (without any reinforcement) was manufactured using the same HIP process and conditions. It is referred to as HIP Ti-6Al-4V alloy here after. The specimen for each test was manufactured by a machining process. The 6-4Ti-W composite could be machined under the same conditions as those for conventional Ti-6Al-4V alloy.

Figure 2 shows the surface observation result of $6-4 \mathrm{Ti}-\mathrm{W}$ composite using a scanning electron microscope. The Ti$6 \mathrm{Al}-4 \mathrm{~V}$ alloy matrix is a fine $\alpha+\beta$ phase. It is observed that the interface of the matrix/fiber is a diffusion phase in

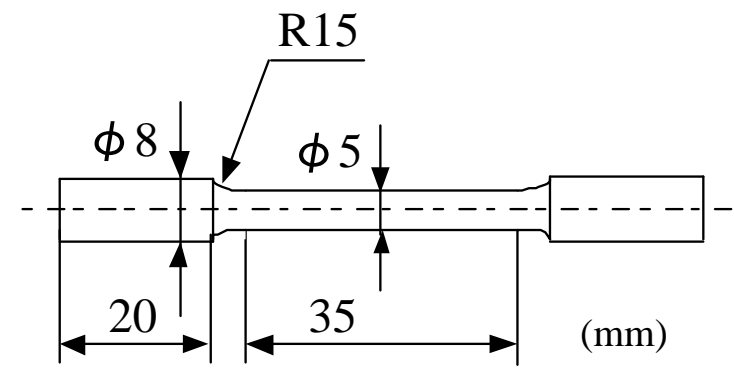

Fig. 3 Shape and dimensions of tensile test specimen.

which the tungsten atom diffuses into the matrix. ${ }^{9)}$ The fibers were almost uniformly distributed, and a large-scale cluster of fibers was not observed. It is observed that tungsten short fibers are oriented in the axial direction of the specimen by the hot forging process. ${ }^{9}$ )

\section{Experimental Methods}

\subsection{Tensile test}

Figure 3 illustrates the shape and dimensions of the tensile test specimen. Tensile tests were carried out on the 6-4Ti-W composite and the HIP Ti-6Al-4V alloy at a tension speed of $0.5 \mathrm{~mm} / \mathrm{min}$ in the room environment. The test was carried out for five test pieces. The elongation was measured by the noncontacting extensometer using two CCD cameras, and the Young's modulus was obtained from the relationship between the strain and the stress.

\subsection{Anodic polarization test}

The anodic polarization test was performed in accordance with JIS (Japanese Industrial Standards) T 0302. Figure 4 illustrates the experimental apparatus used for the above test. These tests were carried out on the 6-4Ti-W composite, the HIP Ti-6Al-4V alloy and the conventional cast Ti-6Al-4V alloy. In addition, the tests were conducted independently in 1 mass\% lactic acid ( $\mathrm{pH}=2.5)$ solution and in Eagle's MEM (Eagle's Minimum Essential Medium) solution. The lactic acid solution was deaerated with high-purity nitrogen gas. The shape of the specimen is $15 \mathrm{~mm}$ in diameter and $5 \mathrm{~mm}$ in height. The specimens were coated with epoxy resin, 

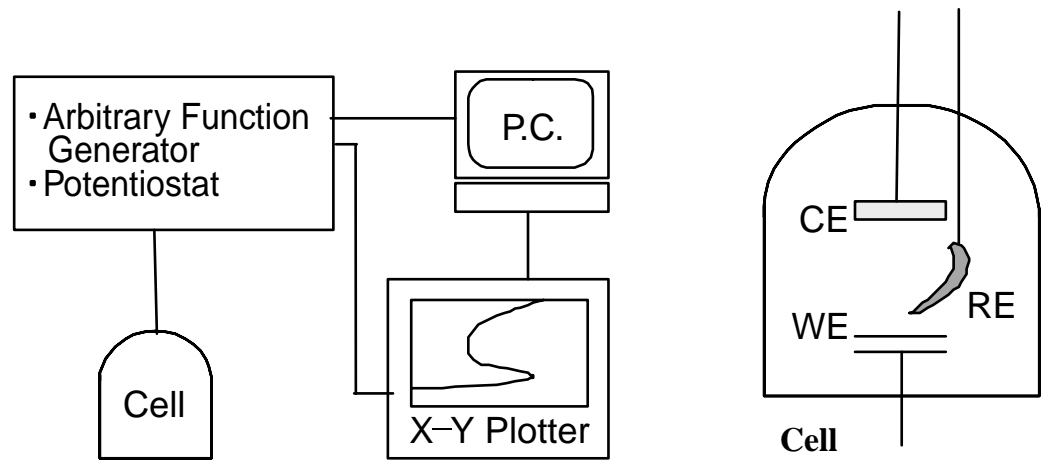

CE: Counter Electrode(Pt)

WE: Working Electrode(Test Specimen)

$\mathrm{RE}:$ Reference Electrode

System of anodic polarization test

Fig. 4 Experimental apparatus for anodic polarization test.

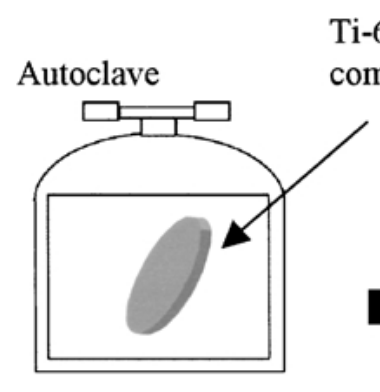

Sterilization in autoclave $121^{\circ} \mathrm{C}, 196 \mathrm{kPa}, 30 \mathrm{~min}$

Ti-6Al-4V + W composite disk

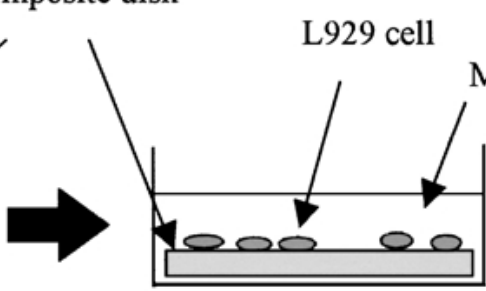

Cell seeding Incubation (4d) $37^{\circ} \mathrm{C}, 5 \% \mathrm{CO}_{2}$

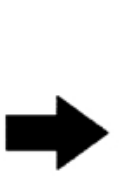

Coulter cup

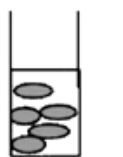

Cell suspension and collection using trypsin

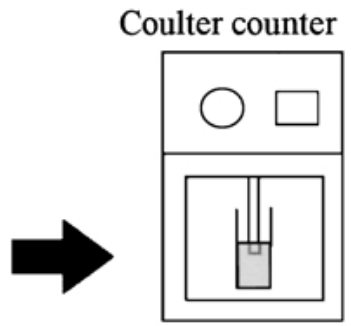

Cell counting by Coulter counter

Fig. 5 Flow chart for cytocompatibility test.

and the surface for the electrode was polished with waterproof emery paper of up to \#1000 grade, and then the specimens were ultrasonically cleaned in ethanol. The anodic polarization test was conducted using an automatic potentiostat in each solution, and the solution was kept at $37^{\circ} \mathrm{C}$ during the test. In the case of the test in lactic acid solution, the specimen was initially held at $-1.0 \mathrm{~V}$ for $300 \mathrm{~s}$ to remove the oxide film from the surface. The anodic polarization test was carried out from $-1.0 \mathrm{~V}$ to a maximum of $5 \mathrm{~V}$ at a sweep rate of $6.67 \times 10^{4} \mathrm{Vs}^{-1}$. A platinum electrode and a saturated calomel electrode were used for the counter electrode and reference electrode, respectively.

\subsection{Cytocompatibility test}

The cytocompatibility test was performed in accordance with JIS T 0301. Figure 5 shows the flow chart for the cytocompatibility test. The relative growth ratio of fibroblast L929 cells on the 6-4Ti-W composite was investigated. The specimen disk was $34 \mathrm{~mm}$ in diameter and $1 \mathrm{~mm}$ in height. After the specimens were polished with waterproof emery paper of up to \#1000 grade, they were ultrasonically cleaned in ethanol. Then, the specimens were sterilized in an autoclave at $121^{\circ} \mathrm{C}$ for $1.8 \mathrm{ks}$ under dry condition. The specimens were placed in a culture dish $35 \mathrm{~mm}$ in diameter. L929 cells were seeded on the 6-4Ti-W composite, the HIP Ti$6 \mathrm{Al}-4 \mathrm{~V}$ and the culture dishes not containing the specimen. $2.8 \mathrm{~mL}$ medium solution and $0.2 \mathrm{~mL}$ cell suspension containing $3.0 \times 10^{4}$ L929 cells were seeded on these specimens. After four days of incubation at $37^{\circ} \mathrm{C}$ in $5 \% \mathrm{CO}_{2}$ atmosphere, the cells were suspended using $0.1 \%$ trypsin-0.02\% EDTA$2 \% \mathrm{Na} / \mathrm{PBS}(-)$. The number of suspended cells in each test medium was counted using a Coulter counter.

\section{Results and Discussion}

\subsection{Tensile properties}

Table 2 shows the result of the tensile test. The tensile strength of the HIP Ti-6Al-4V alloy was approximately $1070 \mathrm{MPa}$. It is considered that the HIP treatment conditions were adequate. The tensile strength and the $0.2 \%$ proof stress of the 6-4Ti-W composite are excellent, approximately $1300 \mathrm{MPa}$ and $1200 \mathrm{MPa}$, respectively. The results of the tensile test indicate that the tungsten short fiber is effective for improving the tensile strength of the Ti-6Al-4V alloy matrix.

Table 3 lists the tensile properties of the existing titanium alloy for a body implant. It is taken from the ISO (International Standardization Organization) and the ASTM (American Society for Testing and Materials) standards. Remarkably, the tensile strength of the developed 6-4Ti-W composite is $350 \mathrm{MPa}$ higher than the standard value given in Table 3. If these excellent mechanical properties are utilized for the design of medical implants, a lighter implant can be manufactured. For example, it could be used as a bone plate or a screw that might need to bear a large load.

\subsection{Corrosion resistance}

As the current density measured by an anodic polarization test is low, the corrosion resistance of a material is excellent, 
Table 2 Tensile properties of composite material and matrix material (average value of experimental results).

\begin{tabular}{lcccc}
\hline & $\begin{array}{c}0.2 \% \text { proof stress } \\
(\mathrm{MPa})\end{array}$ & $\begin{array}{c}\text { Tensile strength } \\
(\mathrm{MPa})\end{array}$ & $\begin{array}{c}\text { Elongation } \\
(\%)\end{array}$ & $\begin{array}{c}\text { Reduction of area } \\
(\%)\end{array}$ \\
\hline HIP Ti-6Al-4V alloy* & 927 & 1071 & 8 & 20 \\
\hline Ti-6Al-4V + W composite & 1208 & 1304 & 2 & 3 \\
\hline
\end{tabular}

*HIP Ti-6Al-4V alloy was manufactured by the same HIP process and conditions.

Table 3 Tensile properties of various titanium alloys for medical implants.

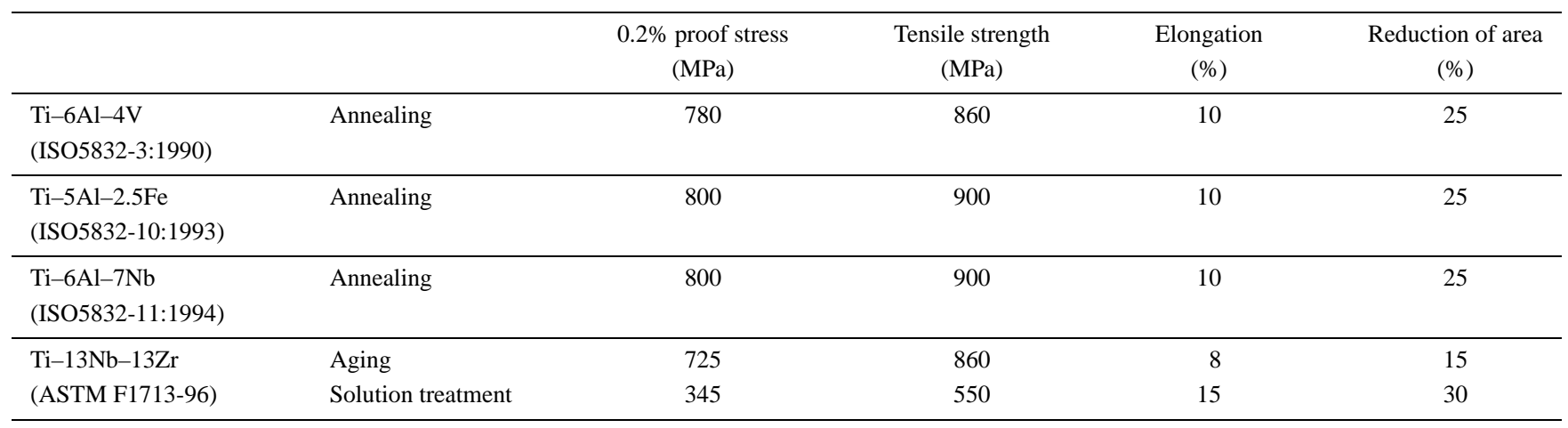

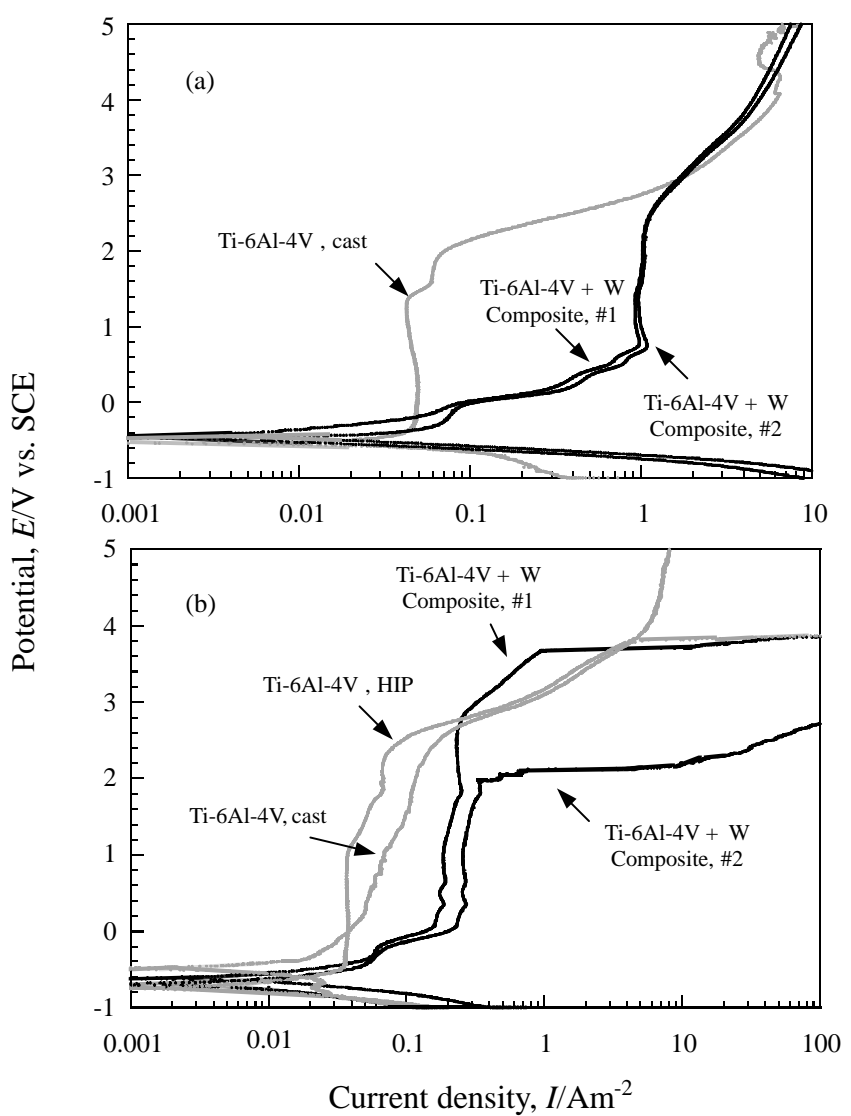

Fig. 6 Comparison of anodic polarization curves for composite material and Ti-6Al-4V alloy in 1 mass\% lactic acid (a) and Eagle's MEM (b) at $37^{\circ} \mathrm{C}$.

in all potential regions. Figure 6 shows the results of the anodic polarization tests. For the $6-4 \mathrm{Ti}-\mathrm{W}$ composite, a similar test was carried out two times (\#1, \#2). A peak of current density for passivation is not observed in all the materials and solutions. In Eagle's MEM solution, the HIP Ti-6Al-4V al-
Table 4 Relative growth ratio of L929 cells on composite material.

\begin{tabular}{lcc}
\hline & Relative growth ratio & Standard deviation \\
\hline Ti-6Al-4V (Control) & 1.000 & - \\
\hline $\begin{array}{l}\text { Ti-6Al-4V }+ \text { W } \\
\text { composite }\end{array}$ & 0.9032 & 0.0271 \\
\hline
\end{tabular}

loy behaves as a conventional cast $\mathrm{Ti}-6 \mathrm{Al}-4 \mathrm{~V}$ alloy. The current density of entrance to the passive region of the 6-4Ti-W composite is higher than that of the Ti-6Al-4V alloy in both solutions. This tendency is significant in 1 mass\% lactic acid. But the passive region of the $6-4 \mathrm{Ti}-\mathrm{W}$ composite is retained to the potential region of about $2 \mathrm{~V}$. This is sufficiently high compared to the potential in vivo.

\subsection{Cytocompatibility}

Table 4 lists the result of the cytocompatibility test. The relative growth ratio is defined as follows: number of cells after incubation on the test material/number of cells on the reference material (control). When the HIP Ti-6Al-4V alloy was the control, the relative growth ratio of the $6-4 \mathrm{Ti}-\mathrm{W}$ composite was 0.9032 . When the culture dish with no specimen was the control, the relative growth ratio of the HIP Ti-6Al-4V alloy was reasonable, being about 0.9 .

Since the relative growth ratio of the $6-4 \mathrm{~T}-\mathrm{W}$ composite was lower than that of the Ti-6Al-4V alloy, the analysis of the metal concentration in the medium after incubation was carried out using an ICP-MS (Inductively Coupled PlasmaMass Spectrometer). The result is shown in Table 5. The concentration of tungsten in the medium after incubation on the 6-4Ti-W composite is 100 times higher than the concentration of tungsten in the control. In addition, because the concentrations of titanium, aluminum and vanadium in Ti-6Al$4 \mathrm{~V}$ alloy and 6-4Ti-W composite were almost equivalent, it is considered that the high-concentration tungsten causes the 
Table 5 Metallic concentration in medium after incubation on Ti-6Al-4V alloy disk and composite material disk (ppb).

\begin{tabular}{lcccc}
\hline & $\mathrm{Ti}$ & $\mathrm{Al}$ & $\mathrm{V}$ & $\mathrm{W}$ \\
\hline Ti-6Al-4V (Control) & 41.91 & 62.34 & 14.42 & 234.2 \\
\hline $\begin{array}{l}\text { Ti-6Al-4V + W } \\
\text { composite }\end{array}$ & 61.28 & 82.0 & 18.75 & 30310 \\
\hline Eagle's medium & 2.725 & 10.91 & 0.16 & 0 \\
\hline
\end{tabular}

decrease of the relative growth ratio of the $6-4 \mathrm{Ti}-\mathrm{W}$ composite. Tungsten was detected from the control medium in which tungsten fiber was not included. Tungsten, which is under $0.5 \mathrm{ppm}$, must be included in the raw material of the Ti-6Al-4V powder. A quantitative investigation of the effect of tungsten ions on the cells is currently being carried out.

Structural biomaterials are inserted in the long term into the body, so the elution of metallic ions should be small. Therefore, in order to improve the cytocompatibility of the composite material, it is considered that another reinforcement material should be used, for example, tantalum fiber, because it is reported that tantalum has excellent corrosion resistance and cytocompatibility. ${ }^{11)}$ In addition, it is considered that the tantalum short fiber reinforced Ti-6Al-4V alloy composite can be manufactured using the same HIP process.

\section{Conclusions}

The tungsten short fiber reinforced Ti-6Al-4V alloy was investigated from the viewpoint of its tensile properties and cytocompatibility. The main results obtained in this study are as follows:

(1) The tensile strength and the $0.2 \%$ proof stress of the tungsten short fiber reinforced Ti-6Al-4V alloy were approximately $1300 \mathrm{MPa}$ and $1200 \mathrm{MPa}$, respectively. These strengths are higher than those of the existing titanium-base biomaterial.

(2) According to the results of anodic polarization tests, the current density of entrance to the passive region of the tungsten short fiber reinforced Ti-6Al-4V alloy was higher than that of Ti-6Al-4V alloy. On the other hand, the passive region of the tungsten short fiber reinforced Ti-6Al-4V alloy was maintained in the potential region of about $2 \mathrm{~V}$, which is sufficiently high in vivo.

(3) When the Ti-6Al-4V alloy was a reference material, the relative growth ratio of the tungsten short fiber reinforced Ti-6Al-4V alloy was 0.9032 .

(4) The concentration of tungsten in the medium after incubation on the tungsten short fiber reinforced Ti-6Al-4V alloy was high compared to that of titanium, aluminum and vanadium. It is considered that the reinforcement should be changed from tungsten fiber to tantalum fiber in order to improve the cytocompatibility.

\section{Acknowledgements}

The authors wish to thank Dr. Yukinori Ono and Mr. Toshihumi Abe, Mechanics \& Electronics Research Institute, Fukuoka Industrial Technology Center for the conduct of experiments. A part of this study had been performed under the sponsorship of Fukuoka Industry, Science \& Technology Foundation.

\section{REFERENCES}

1) Y. Okazaki, K. Kyo, Y. Ito, E. Nishimura and T. Tateishi: Materia Japan 36 (1997) 1092-1099.

2) Y. Okazaki, S. Rao, Y. Ito and T. Tateishi: Biomaterials 19 (1998) 11971215.

3) Y. Okazaki, S. Rao, T. Tateishi and Y. Ito: Mater. Sci. Eng. A 243 (1998) 250-256.

4) M. F. Semlitsch, H. Weber, R. M. Streicher and R. Schon: Biomaterials 13 (1992) 781-788.

5) M. Semlitsch, F. Staub and H. Weber: Biomedizinische Technik 30 (1985) 334-339.

6) Y. Higo, Y. Tomita, K. Murota and H. Sugiyama: Proc. 3rd Japan International SAMPE Symposium, (1993) pp. 1621-1625.

7) D. Kuroda, M. Niinomi, H. Fukui, M. Morinaga, A. Suzuki and J. Hasegawa: Tetsu-to-Hagane 86 (2000) 602-609.

8) T. Hayashi: The composite material engineering, (1988) pp. 3-24.

9) S. Nishida, K. Hayashi, N. Hattori, K. Nakano, Y. Yanagida and H. Tamasaki: Key Engineering Materials, (Trans. Tech. Publications, Switzerland, 2000) pp. 1243-1248.

10) Y. Okazaki, S. Rao, S. Asao, T. Tateishi, S. Katsuda and Y. Furuki: J. Japan Inst. Metals 60 (1996) 890-896.

11) Y. Okazaki: Materia Japan 37 (1998) 838-842. 